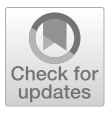

Cite as

Nano-Micro Lett.

(2022) 14:31

Received: 15 September 2021

Accepted: 3 November 2021

Published online: 13 December 2021

(c) The Author(s) 2021

\section{Manipulating Interfacial Stability Via Absorption-Competition Mechanism for Long-Lifespan Zn Anode}

\author{
Meijia Qiu ${ }^{1,2}$, Liang $\mathrm{Ma}^{2}$, Peng Sun ${ }^{1,2}$, Zilong Wang $^{2}$, Guofeng Cui ${ }^{1} \bowtie$, Wenjie Mai ${ }^{2}$
}

\title{
HIGHLIGHTS
}

- Aromatic aldehyde additives were introduced to modify the interfacial environment between $\mathrm{Zn}$ sheet and electrolyte through an absorption-competition mechanism, thus effectively inhibiting the dendrite/by-products growth.

- $\mathrm{Zn}-\mathrm{Zn}$ and $\mathrm{Zn}-\mathrm{MnO}_{2}$ cells with the additives achieved much better cycling stability (over $3000 \mathrm{~h}$ under $1 \mathrm{~mA} \mathrm{~cm}^{-2} / 1 \mathrm{mAh} \mathrm{cm}{ }^{-2}$ and $800 \mathrm{~h}$ under $5 \mathrm{~mA} \mathrm{~cm}{ }^{-2} / 5 \mathrm{mAh} \mathrm{cm}^{-2}$ for symmetric cells) than that of pure $\mathrm{ZnSO}_{4}$ electrolyte.

ABSTRACT The stability of $\mathrm{Zn}$ anode in various $\mathrm{Zn}$ based energy storage devices is the key problem to be solved. Herein, aromatic aldehyde additives are selected to modulate the interface reactions between the $\mathrm{Zn}$ anode and electrolyte. Through comprehensively considering electrochemical measurements, DFT calculations and FEA simulations, novel mechanisms of one kind of aromatic aldehyde, veratraldehyde in inhibiting $\mathrm{Zn}$ dendrite/by-products can be obtained. This additive prefers to absorb on the $\mathrm{Zn}$ surface than $\mathrm{H}_{2} \mathrm{O}$ molecules and $\mathrm{Zn}^{2+}$, while competes with hydrogen evolution reaction and $\mathrm{Zn}$ plating/stripping process via redox reactions, thus preventing the decomposition of active $\mathrm{H}_{2} \mathrm{O}$ near the interface and uncontrollable $\mathrm{Zn}$ dendrite growth via a synactic absorption-competition mechanism.
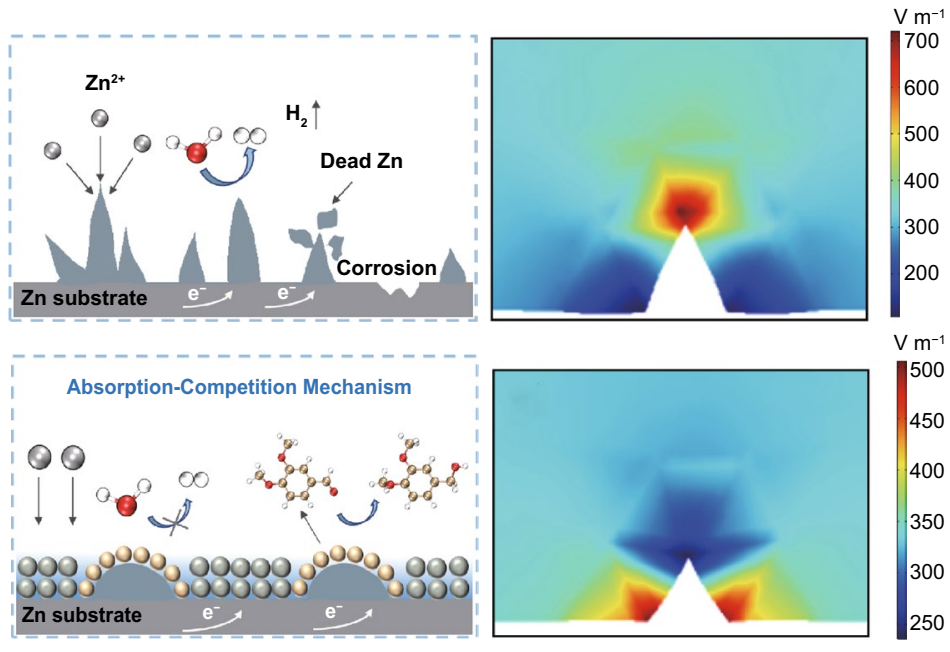

As a result, Zn-Zn symmetric cells with the veratraldehyde additive realize an excellent cycling life of $3200 \mathrm{~h} \mathrm{under} 1 \mathrm{~mA} \mathrm{~cm}^{-2} / 1 \mathrm{mAh}$ $\mathrm{cm}^{-2}$ and over $800 \mathrm{~h}$ even under $5 \mathrm{~mA} \mathrm{~cm} / 5 \mathrm{mAh} \mathrm{cm}{ }^{-2}$. Moreover, $\mathrm{Zn}-\mathrm{Ti}$ and $\mathrm{Zn}-\mathrm{MnO}_{2}$ cells with the veratraldehyde additive both obtain elevated performance than that with pure $\mathrm{ZnSO}_{4}$ electrolyte. Finally, two more aromatic aldehyde additives are chosen to prove their universality in stabilizing $\mathrm{Zn}$ anodes.

KEYWORDS Aromatic aldehyde; Absorption-competition mechanism; Zn anode; Interfacial stability

$\checkmark$ Guofeng Cui, cuigf@mail.sysu.edu.cn

1 Key Laboratory for Polymeric Composite \& Functional Materials of Ministry of Education, School of Chemistry, Key Laboratory of Low-Carbon Chemistry \& Energy Conservation of Guangdong Province, Sun Yat-Sen University, Guangzhou 510275, People's Republic of China

2 Siyuan Laboratory, Guangdong Provincial Engineering Technology Research Center of Vacuum Coating Technologies and New Energy Materials, Guangzhou Key Laboratory of Vacuum Coating Technologies and New Energy Materials, Department of Physics, Jinan University, Guangdong 510632, People's Republic of China 


\section{Introduction}

The strong demands toward environmentally friendly and sustainable energy storage devices have propelled the fast development of aqueous batteries [1]. Zn metal due to its proper potential $(-0.76 \mathrm{~V}$ vs. SHE), high volumetric capacity $\left(5855 \mathrm{mAh} \mathrm{cm}^{-3}\right)$ and low-cost, has been applied in all kinds of $\mathrm{Zn}$-based aqueous batteries with considerable performance such as $\mathrm{Zn}$ ion, $\mathrm{Ni}-\mathrm{Zn}, \mathrm{Ag}-\mathrm{Zn}$ and electrolytic $\mathrm{Zn}-\mathrm{MnO}_{2}$ batteries [2-5]. The key issues inside $\mathrm{Zn}$-based energy storage devices lie in the complex interface chemistry reaction easily causing partial failure of $\mathrm{Zn}$ metal anodes, thus usually resulting in dendrites, corrosion and by-products problems [6]. To tackle the above matters are of great significance to further progress of $\mathrm{Zn}$-based devices and deeper understanding for their intrinsic mechanisms.

Great efforts on solving the severe problems in $\mathrm{Zn}$ metal anodes have been proposed by previous researches, most of which involved modification on $\mathrm{Zn}$ anode/electrolyte interface and the solvation structure of electrolyte [7-9]. For instance, strategies like decorating protective layers/ solid electrolyte interphase [10-19], selecting proper separators, constructing three-dimensional alloy structure or regulating crystal orientation could effectively control the $\mathrm{Zn}$ ion diffusion and deposition rate [18, 20-27], while cut off the pathway of hydrogen evolution reaction (HER), random corrosion and by-products formation to some extent. Besides, another type of important methods focused mainly on designing the composition or state of the electrolyte to change the primary solvation shell constitution or the environment in $\mathrm{Zn}$ anode/electrolyte interface, achieving similar functions mentioned before, including introducing different solvent into pure water or small amount of additives [28-33], constructing highly concentrated "water in salt" structure and utilizing ionic liquid, eutectic liquid, hydrogels or solidstate electrolyte [34-38].

The electrolyte is one of the most important components in $\mathrm{Zn}$-based energy storage devices due to the bridge function of connecting the cathode and anode while providing a pathway for $\mathrm{Zn}$ ions migration [39]. Through choosing proper additives into main $\mathrm{Zn}$ salts is a simple, cheap and easy to batch method. Moreover, the complex chemical interaction between additives with the bulk electrolyte or $\mathrm{Zn}$ anode surface is deserved to be explored for deeper understanding [40]. In traditional electroplating industry, there exists some brighteners achieving polished deposition via a redox mechanism, which should also be suitable for reversible $\mathrm{Zn}$ plating/stripping process inside all kinds of Zn-based aqueous batteries. It's obvious a charming idea to adopt them as additives into pure electrolytes for suppressing the occurrence of dendrite/by-reactions.

We hereby proposed a type of aromatic aldehyde as additives in traditional $\mathrm{ZnSO}_{4}$ electrolyte to greatly elevate the stability of $\mathrm{Zn}$ plating/stripping in $\mathrm{Zn}$ ion batteries by restricting the dendrite growth and all kinds of by-reactions through an absorption-competition mechanism. Combing density functional theory (DFT) calculations and corresponding electrochemical experiments, it can be conferred the aromatic aldehyde additives preferred absorbed onto $\mathrm{Zn}$ metal that are capable of inhibiting common by-reactions while encountering reduction before HER and $\mathrm{Zn}$ deposition process at the initial nuclear process, together achieving long-lifespan $\mathrm{Zn}$ anode. As a proof of concept, the $\mathrm{Zn}-\mathrm{Zn}$ symmetric cell, $\mathrm{Zn}-\mathrm{Ti}$ and $\mathrm{Zn}-\mathrm{MnO}_{2}$ devices under different electrolyte systems were fabricated and compared, confirming those aromatic aldehyde additives owned the ability to relieve the dendrite/by-products issues in $\mathrm{Zn}$ anodes.

\section{Experimental Section}

\subsection{Fabrication of $\mathrm{Zn}-\mathrm{Zn}$ Symmetric Cell and $\mathrm{Zn}-\mathrm{Ti}$ Cells}

A pair of $\mathrm{Zn}$ foils of $100 \mu \mathrm{m}$ were used for constructing the symmetric cells. Different electrolyte composition (pure for $1 \mathrm{M} \mathrm{ZnSO}_{4}$ and $\mathrm{ZnSO}_{4}$-veratraldehyde for $1 \mathrm{M} \mathrm{ZnSO}_{4}$ with different concentration of veratraldehyde) each with $75 \mu \mathrm{L}$ were added into the coin cell separated via a piece of glass fiber (GE-Whatman, $125 \mathrm{~mm}$ ). As for Zn-Ti cells, we just changed the two $\mathrm{Zn}$ foils as one $\mathrm{Zn}$ foil as anode and one $\mathrm{Ti}$ foil as cathode, keeping the other condition same as $\mathrm{Zn}-\mathrm{Zn}$ cells.

\subsection{Fabrication of $\mathrm{Zn}-\mathrm{MnO}_{2}$ Full Cell}

$\mathrm{MnO}_{2}$ was prepared on carbon cloth through electrodeposition method following our previous work [33, 41]. Firstly, carbon cloth was washed with acetone, ethanol and deionized water each for 10 min under ultrasonic bath before the electrodeposition process. Typical, a plating solution 
containing $0.1 \mathrm{M} \mathrm{MnAc}_{2}$ and $0.1 \mathrm{M} \mathrm{Na}_{2} \mathrm{SO}_{4}$ was used to synthesize $\mathrm{MnO}_{2}$ in a three-electrode system with the $\mathrm{Ag}$ / $\mathrm{AgCl}$ as reference and a carbon rod as counter electrodes. The electrodeposition condition was set to be $4 \mathrm{~mA} \mathrm{~cm}{ }^{-2}$ for $10 \mathrm{~min}$.

\subsection{Electrochemical Test}

The performances of $\mathrm{Zn}-\mathrm{Zn}, \mathrm{Zn}-\mathrm{Ti}$ cells and $\mathrm{Zn}-\mathrm{MnO}_{2}$ full cells were collected by battery test system (Neware BTS-4000). For Zn-Zn cells, constant current densities were applied ranging from $1,2,5 \mathrm{~mA} \mathrm{~cm}^{-2}$, and the charging and discharging times were both set to be $1 \mathrm{~h}$. For $\mathrm{Zn}$-Ti cells, a reversible testing condition was set to be $1 \mathrm{~mA} \mathrm{~cm}^{-2}$ with a charging and discharging time each for $0.5 \mathrm{~h}$. For $\mathrm{Zn}-\mathrm{MnO}_{2}$ cells, the voltage range was $1-1.9 \mathrm{~V}$ under different current densities (range from 0.1 to $1 \mathrm{~A}$ $\mathrm{g}^{-1}$ ). The corrosion, diffusion and hydrogen evolution behaviors of $\mathrm{Zn}$ foil anodes in different electrochemical environments were both studied through an electrochemical workstation (CHI 660e) with a three-electrode system ( $\mathrm{Zn}$ foil as work electrode, $\mathrm{Pt}$ as counter electrode and $\mathrm{Ag} / \mathrm{AgCl}$ as reference electrode). The corrosion Tafel plot was recorded by performing linear voltammetry scanning (LSV) with a potential range of $\pm 0.3 \mathrm{~V}$ versus open-circle potential of the system at a scan rate of $1 \mathrm{mV} \mathrm{s}^{-1}$. The diffusion curves were collected by chronoamperometry method at an overpotential of $-150 \mathrm{mV}$. The hydrogen evolution performance was collected through LSV with a potential range of $-0.9 \sim-1.6 \mathrm{~V}$ versus $\mathrm{Ag} / \mathrm{AgCl}$ at a scan rate of $1 \mathrm{mV} \mathrm{s}^{-1}$.

\subsection{Characterization}

The in-situ microscope images for $\mathrm{Zn}$ deposition process were obtained by commercial high-resolution camera (Mshot, MS60) equipped a magnifying glass holder, the same as our previous work [33]. The morphology of $\mathrm{Zn}$ foil before and after deposition or cycles were characterized by field-emission scanning electron microscopy (SEM, ZEISS ULTRA 55). The crystal structure and material composition information were gathered by X-ray diffraction (XRD, Rigaku, MiniFlex600, $\mathrm{Cu} \mathrm{K \alpha}$ ).

\subsection{DFT Calculations}

\subsubsection{Quantum Chemistry Calculations}

DFT calculation were conducted in Gaussian (G09) program [42]. The structure optimization was performed at B3LYP with 6-31 $\mathrm{g}$ * basis set. Then a single-point energy calculation of each optimized structure was performed at the same hybrid functional with $6311 \mathrm{~g} *$ basis set. The electrostatic potential (ESP) was analyzed by Multiwfn package and VMD package [43, 44].

\subsubsection{Ab-Initial Calculations}

The calculation related to the interaction between $\mathrm{Zn}$ crystal and molecules were performed by using the Vienna abinitio Simulation Package (VASP). The projector augmented wave (PAW) potential was employed to represent the interactions of electrons with ion cores. The generalized gradient approximation (GGA) parameterized by the Perdew-BurkeErnzerhof (PBE) method with D3 correction that was used to describe the system [45]. Implicit solvent model $\left(\mathrm{H}_{2} \mathrm{O}\right.$ around) was also introduced in all absorption energy calculations. All calculations including geometry optimization, single-point energy and electronic density were carried out within a $13.3245 \times 11.5393 \times 22.4202 \AA^{3}$ box under a periodic boundary condition and a dense Monkhorst-Pack k point mesh of $2 \times 2 \times 1$. A high energy cutoff of $500 \mathrm{eV}$ and the forces acting on all the ions smaller than $0.01 \mathrm{eV} \AA^{-1}$ were set. On the $\mathrm{Z}$ direction, there is $15 \AA$ vacuum for erasing the effect of periodic condition for slab model. A $5 \times 5$ supercell with four-layer $\mathrm{Zn}$ slab (002) was used to represent the absorbed surface for molecules, and the bottom two layers were kept fixed to maintain bulk property. The charge differential density was calculated through the software Vesta. The specific tool Vaspkit was used for the Free-energy correction in calculating several $\Delta \mathrm{G}$ values [46]. The absorbed energy between $\mathrm{Zn}$ slab and different molecules was defined as following equation:

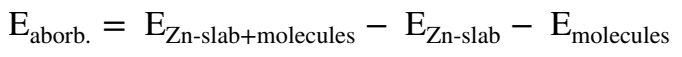

\subsection{Finite Element Analysis Method}

The simplified 2D model geometry consists of two electrodes and an intermediate electrolyte domain. This simulation uses 
the electric field intensity and currents to present the difference between two electrolyte system models. The variable for the normal current density defines the mesh velocity. The positive electrode has some protrusions, representing uneven deposition of $\mathrm{Zn}$. Before and after covered by aldehyde molecules, the electronic conductivity of the protrusions is set to change drastically.

\section{Results and Discussion}

\subsection{Observation of Electrolyte Engineering with Veratraldehyde}

One of the commonly used aromatic aldehyde spice, veratraldehyde was selected first. As presented in Fig. 1a, it can be derived from a plant called burley tobacco, thus is eco-friendly and abundant in source. The intuitive function for inhibiting dendrite growth was firstly observed through in-situ optical microscopy images under a deposition condition of $5 \mathrm{~mA} \mathrm{~cm}{ }^{-2}$ with pure $\mathrm{ZnSO}_{4}$ and $\mathrm{ZnSO}_{4}$-veratraldehyde electrolytes in Fig. $1 \mathrm{~b}$, c, respectively. Ti foils were used as the anode to deposit $\mathrm{Zn}$ due to their small lattice mismatch (lattice misfit equals 9\%) [24]. Non-uniform growth of $\mathrm{Zn}$ metals or other by-products could gradually be found on the Ti foil as the plating process continued under pure $\mathrm{ZnSO}_{4}$ electrolyte (Movie S1). However, for the sample within an environment containing a small amount of veratraldehyde $\left(0.3 \mathrm{~g} \mathrm{~L}^{-1}\right)$, only smooth and plain deposited layer existed on the Ti foil (Movie S2). These results provide the preliminary evidence that veratraldehyde is a valid additive for stabilizing $\mathrm{Zn}$ anode. Subsequently, two $\mathrm{Zn}$ sheets were coupled into a symmetric cell for reversible plating/stripping test. After 50 cycles under a current density of $5 \mathrm{~mA} \mathrm{~cm}^{-2}$ and

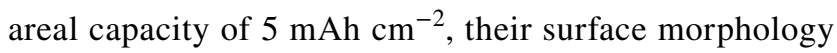
under different electrolyte system was compared through scanning electron microscope (SEM), as demonstrated in Fig. 1d, e and S1. Prominent aggregations of uneven $\mathrm{Zn}$ and by-products deposition were caught everywhere in the sample experiencing cyclic deposition/dissolution in pure $\mathrm{ZnSO}_{4}$ electrolyte. In sharp contrast, a uniform and plain layer could be discovered on the surface of the Zn sheets encountering the same reversible plating/stripping process in a electrolyte with veratraldehyde additive. Besides, X-Ray diffraction (XRD) measurements were performed for above two kinds $\mathrm{Zn}$ sheets after long plating/stripping cycles under different electrolytes. The peak for common by-product $\left.\left(\mathrm{Zn}(\mathrm{OH})_{2}\right)\right)_{3}\left(\mathrm{ZnSO}_{4}\right)-\left(\mathrm{H}_{2} \mathrm{O}\right)_{3}$ at $2 \theta=9.7^{\circ}$ can be easily observed in the sample under pure $\mathrm{ZnSO}_{4}$ electrolyte. In reverse, $\mathrm{Zn}$ sheets under the $\mathrm{ZnSO}_{4}$-veratraldehyde electrolyte exhibit totally no impurity peak but the similar peaks as pure $\mathrm{Zn}$ sheet. These characterizations further indicate the essential role of the veratraldehyde additive in solving the dendrite problem on $\mathrm{Zn}$ anodes. The absorption behavior of the veratraldehyde additive was examined through $\mathrm{X}$-ray photoelectron spectroscopy (XPS) analysis. One Zn sheet was soaked into $0.3 \mathrm{~g} \mathrm{~L}^{-1}$ veratraldehyde solution and performed this test. From the XRD results in Fig. S2, it can be conferred that no by-products can be found on the treated $\mathrm{Zn}$ sheet. As presented in Fig. 1g, h, peaks located at $284.68 \mathrm{eV}$, $286.38 / 531.58 \mathrm{eV}$ and $288.48 / 533.18 \mathrm{eV}$ from $\mathrm{C} 1 \mathrm{~s}$ and $\mathrm{O}$ $1 \mathrm{~s}$ are corresponding to $\mathrm{C}-\mathrm{C} / \mathrm{C}=\mathrm{C}$ of benzene ring, $\mathrm{C}-\mathrm{O}$ and $\mathrm{C}=\mathrm{O}$ all derived from the veratraldehyde molecule, respectively, while the peak at $530.28 \mathrm{eV}$ might belong to $\mathrm{Zn}-\mathrm{O}$ due to the interaction between the $\mathrm{Zn}$ sheet and veratraldehyde or some by-products oxidized by $\mathrm{H}_{2} \mathrm{O} / \mathrm{O}_{2}$ molecules in the electrolyte/air interface (proved by the XPS result from $\mathrm{Zn}$ sheet soaked in DI water for a day, Fig. S2) [47-49], while the peak located at $1021.88 \mathrm{eV}$ appeared a small shift toward higher binding energy in $\mathrm{Zn} 2 \mathrm{p}$ compared with pure $\mathrm{Zn}$ sheet (shown in Fig. S3), indicating that this additive can be loaded on $\mathrm{Zn}$ surface via a chemical absorption function.

\subsection{Interfacial Interaction Between the $\mathrm{Zn}$ Anode and Electrolyte}

In order to figure out the exact mechanism of the veratraldehyde additive in inhibiting dendrite/by-products growth, DFT calculations combined with several electrochemical experiments were conducted. Due to the complex but important issues happened in the interface between the $\mathrm{Zn}$ metal and electrolyte, our research mainly pointed on their interfacial interactions. Ab-initio calculations were firstly performed to study the absorption ability of different molecules/ions on Zn metal slab-(002) crystal plane, exhibited in Fig. 2a. Various possible absorbed sites (details shown in Fig. S4) for $\mathrm{H}_{2} \mathrm{O}$, veratraldehyde molecules and $\mathrm{Zn}$ ions were all taken into account. Results demonstrated that 


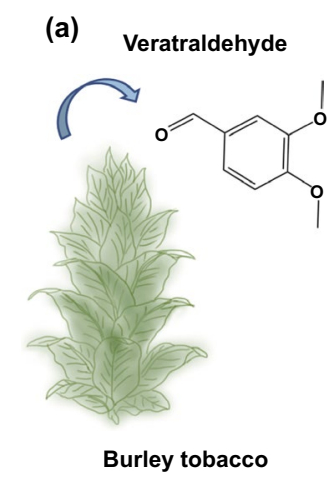

(b)
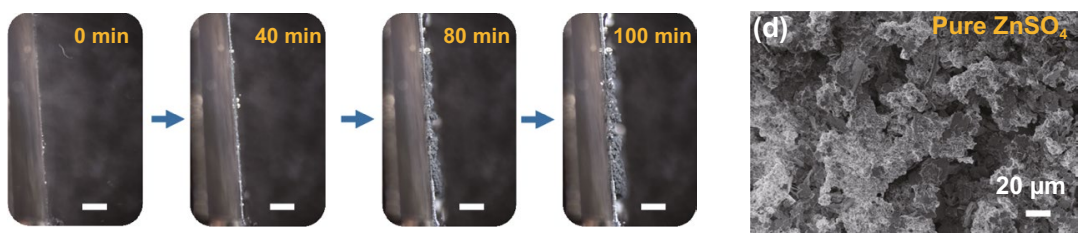

(c)
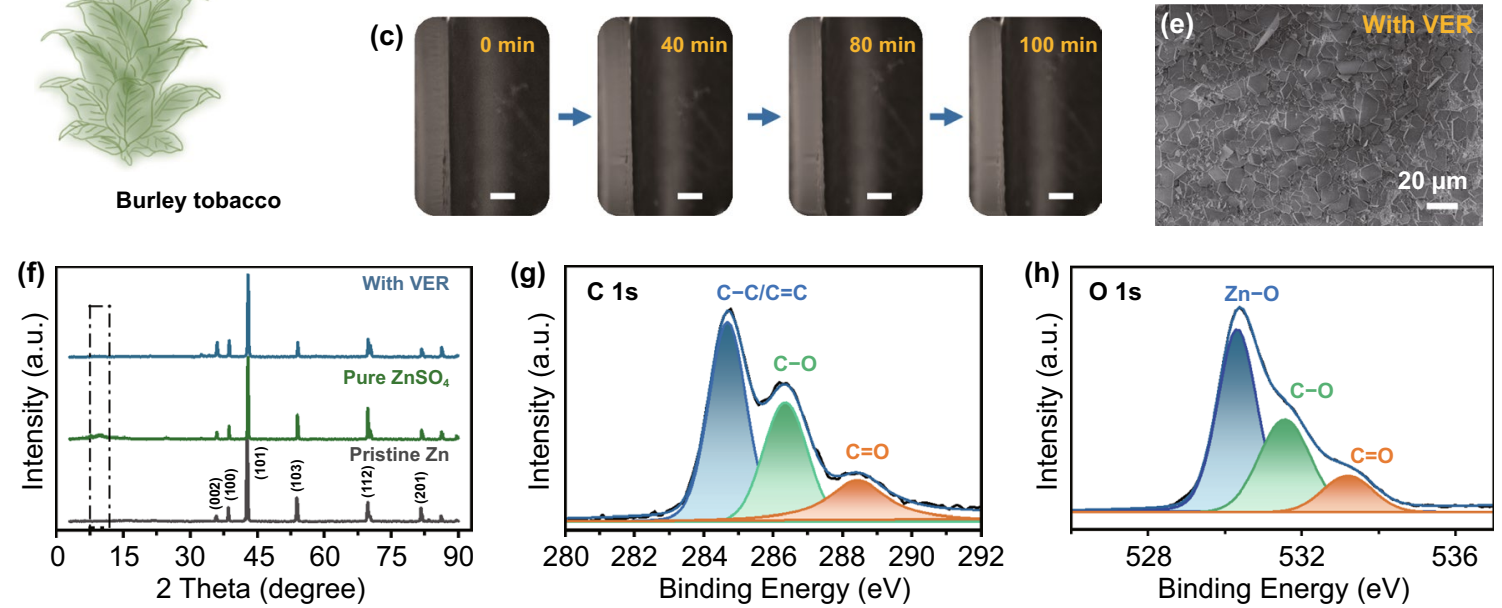

Fig. 1 Comparison of $\mathrm{Zn}$ plating/stripping results under different electrolytes via morphology and constituent characterization. a Scheme represents one of the most common source of veratraldehyde and its molecular structure; In-situ recording microscopy images of $\mathrm{Zn}$ deposition process on the $\mathrm{Ti}$ sheet in a $\mathrm{Zn} / / \mathrm{Ti}$ system under $\mathbf{b} \mathrm{ZnSO}_{4}$ and $\mathbf{c} \mathrm{ZnSO}_{4}$-veratraldehyde environments, white scale bar: $200 \mu \mathrm{m}$; SEM images of $\mathrm{Zn}$ sheet surface after 50 plating/stripping cycles in $\mathrm{Zn} / / \mathrm{Zn}$ symmetric cells with a test condition of $5 \mathrm{~mA} \mathrm{~cm}{ }^{-2}, 5 \mathrm{mAh} \mathrm{cm}^{-2}$ under $\mathbf{d ~ Z n S O}$, $\mathbf{e Z n S O}_{4}$-veratraldehyde electrolytes and $\mathbf{f}$ their corresponding XRD patterns. The High-resolution XPS spectra of the $\mathrm{Zn}$ sheet: $\mathbf{g} \mathrm{C} 1 \mathrm{~s}$ and $\mathbf{h} \mathrm{O}$ $1 \mathrm{~s}$ after soaked in $0.3 \mathrm{~g} \mathrm{~L}^{-1}$ veratraldehyde solution for a week

there existed weak interaction between $\mathrm{H}_{2} \mathrm{O}$ and $\mathrm{Zn}$ slab (the most stable site lied in TOP, the absorption energy $\mathrm{E}_{\mathrm{abs}}$ only reached $-0.23 \mathrm{eV}$ ). For the situation of $\mathrm{Zn}$ ions loaded on $\mathrm{Zn}$ slab, rather strong absorptive function could be observed, with all $\mathrm{E}_{\mathrm{abs}}$ over $-0.60 \mathrm{eV}$, which even exceeded those models of $\mathrm{Zn}$ slab with vertically aligned veratraldehyde molecules (Zn-VER-V), no matter which kinds of sites. However, when veratraldehyde was arranged on $\mathrm{Zn}$ slab parallelly (Zn-VER-P), it presented the highest $\mathrm{E}_{\text {abs }}(-1.06 \mathrm{eV})$. The interaction between the $\mathrm{Zn}$ anode and veratraldehyde molecules was further studied through charge density difference calculations in Fig. 2b. Apparent charge transfer could be observed between the two objects, indicating a fairly strong chemical absorption behavior. In addition, electrochemical measurements including nucleation overpotential and electrochemical impedance spectroscopy (EIS) under different electrolytes were compared. As presented in Fig. $\mathrm{S} 5, \mathrm{Zn}-\mathrm{Zn}$ cells using the $\mathrm{ZnSO}_{4}$-veratraldehyde electrolyte possessed a higher charge transfer resistance (346.1 $\Omega$ ) and nucleation overpotential $(93.6 \mathrm{mV})$ than that with pure $\mathrm{ZnSO}_{4}$ electrolyte ( $65.1 \Omega$ and $50.9 \mathrm{mV}$ ), further proving the absorption behavior of the veratraldehyde additive. Thus, it can be inferred that the veratraldehyde molecule preferred to interact with $\mathrm{Zn}$ anode than the $\mathrm{H}_{2} \mathrm{O}$ molecule and $\mathrm{Zn}$ ions and help to control the $\mathrm{Zn}$ ion diffusion process, as also proved via the chronoamperometry measurements in Fig. S6. Under an overpotential of $-150 \mathrm{mV}$, the current density under pure $\mathrm{ZnSO}_{4}$ system continuously decreased without slowing the damping speed till $600 \mathrm{~s}$, representing an uncontrollably rampant $2 \mathrm{D}$ and subsequent $3 \mathrm{D}$ diffusions. On the contrary, that one with the veratraldehyde additive presented mild variation of current density as time went by, and reached a steady state finally, which is in accordance with the constrained 2D diffusion behavior. Moreover, the system with the veratraldehyde additive could greatly change the onset potential of HER to negative side (over $200 \mathrm{mV}$ variation), inducing larger overpotential (163 mV difference) under the current density of $10 \mathrm{~mA} \mathrm{~cm} \mathrm{~cm}^{-2}$ (Fig. 2c). Similar results could further be proved according to theoretical calculations for the free energy of hydrogen adsorption $(\mathrm{G})$ on $\mathrm{Zn}$ (002) slab, as shown in Fig. 2d. Obviously, a higher variation of $\mathrm{G}(\Delta \mathrm{G})$ of $-0.67 \mathrm{eV}$ under the electrolyte system 
(a)
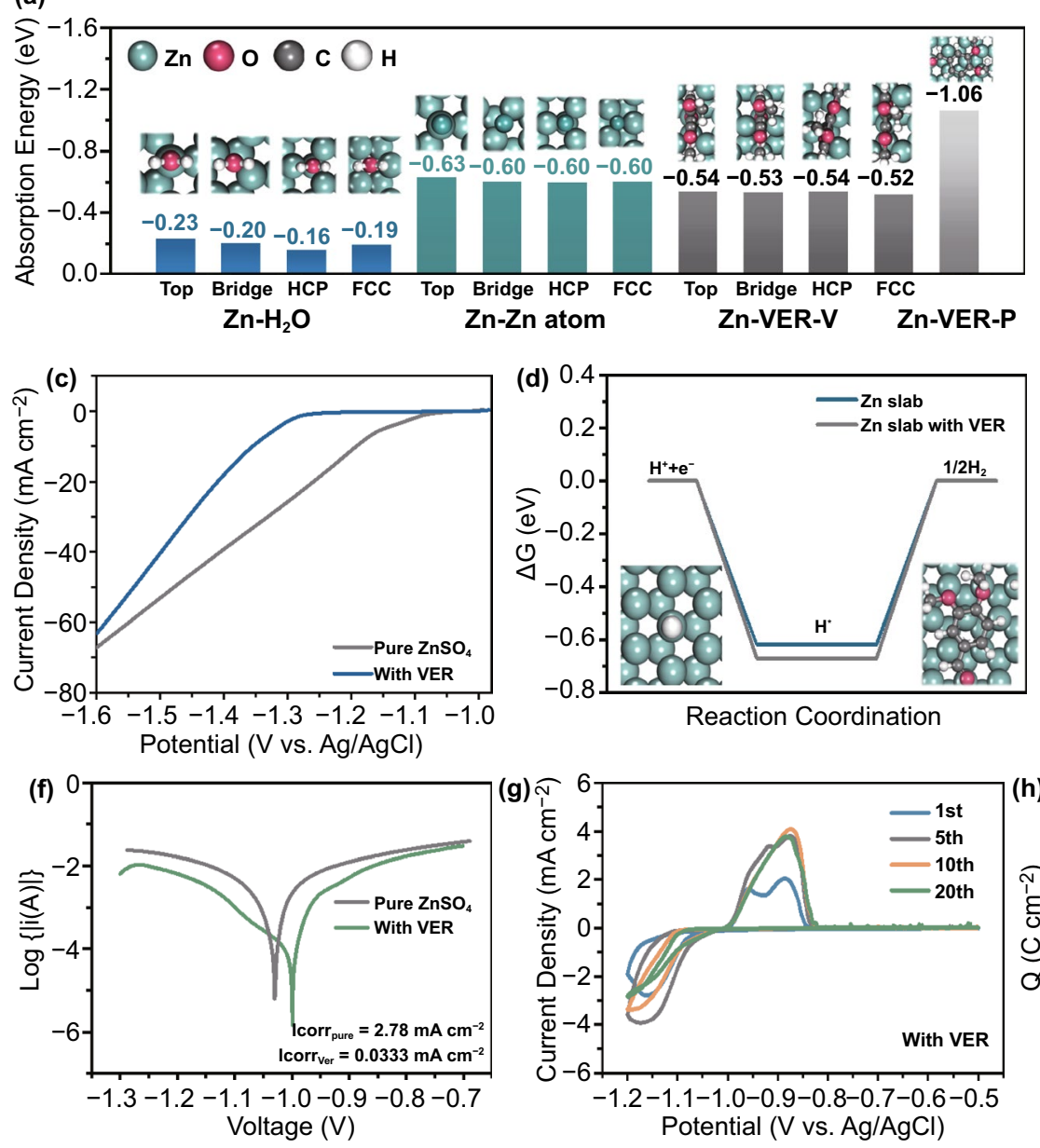

(i)

ESP

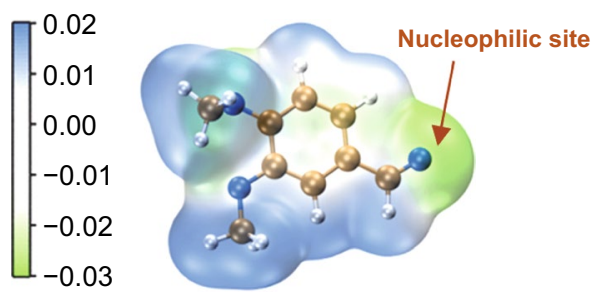

(b)

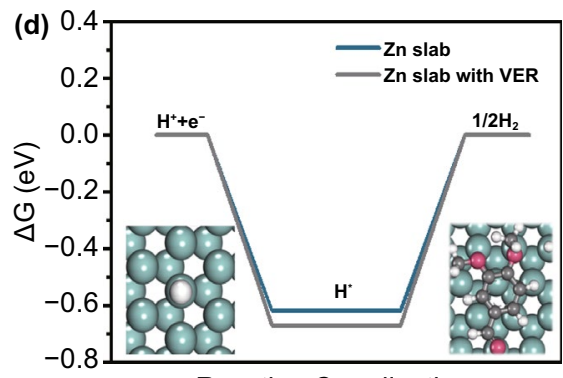

Reaction Coordination
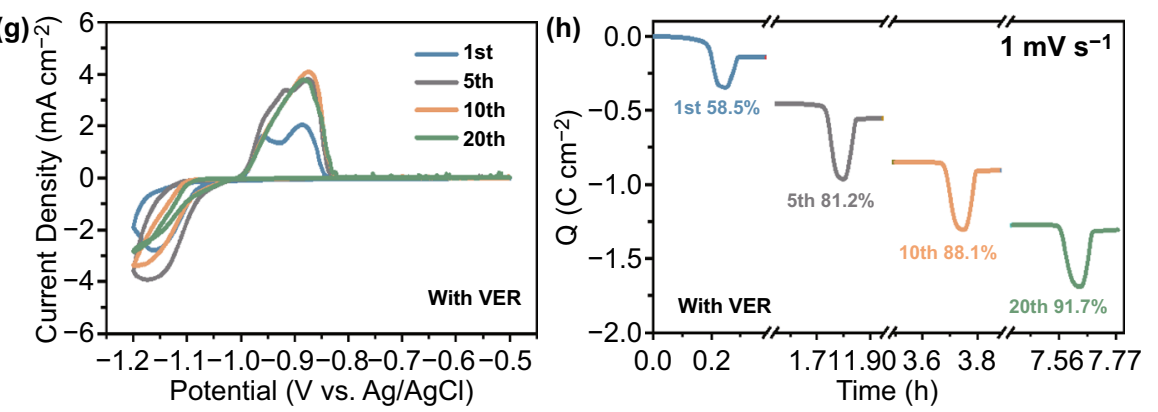

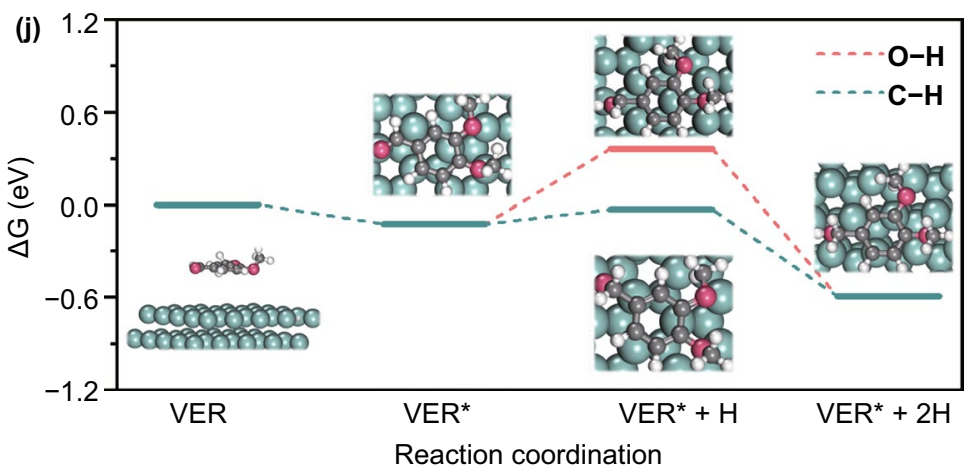

Fig. 2 Electrochemical measurements and DFT calculations for exploiting the function of the veratraldehyde additive inside $\mathrm{ZnSO}_{4}$ electrolyte. a Absorption energy comparison of $\mathrm{Zn}$ atom, $\mathrm{H}_{2} \mathrm{O}$ and veratraldehyde molecules on $\mathrm{Zn}(002)$ crystal plane, insets show the corresponding absorbed models for different situations; $\mathbf{b}$ The charge density difference model of $\mathrm{Zn}$ slab with parallelly placed veratraldehyde and the corresponding isosurface (yellow and cyanine semi-transparent clusters represent increase and decrease of electron density, respectively); Comparison of $\mathbf{c}$ the HER performance and $\mathbf{d}$ the free-energy graphs of the HER processes between pure $\mathrm{ZnSO}_{4}$ and $\mathrm{ZnSO}_{4}$-veratraldehyde electrolytes; $\mathbf{e}$ LUMO, HOMO isosurfaces (isovalue $=0.02$ a. u.) of veratraldehyde (left) and water molecules (right); $\mathbf{f}$ Comparison of Tafel plots representing the corrosion behavior under different electrolytes; $\mathbf{g ~ C V}$ curves of $\mathrm{Zn}$ plating/stripping at a scan rate of $1 \mathrm{mV} \mathrm{s}^{-1}$ in the $\mathrm{ZnSO}_{4}$-veratraldehyde electrolyte and $\mathbf{h}$ the corresponding chronocoulometry curves based on the above CV curves; $\mathbf{i}$ Electrostatic potential mapping of one veratraldehyde molecule indicating the obvious nucleophilic site; $\mathbf{j}$ Possible reaction pathways for veratraldehyde reduced to veratryl alcohol on the surface of Zn slab 
with the veratraldehyde additive versus $-0.62 \mathrm{eV}$ under a pure $\mathrm{ZnSO}_{4}$ electrolyte exhibited the better inhibition function of the veratraldehyde for the HER process, well in line with above experimental results. Comparison of molecular orbital level between the veratraldehyde and $\mathrm{H}_{2} \mathrm{O}$ molecules was performed afterward, as shown in Fig. 2e. The veratraldehyde delivers a lower position of the lowest unoccupied molecular orbital (LUMO) than that of $\mathrm{H}_{2} \mathrm{O}(-1.777$ vs. $-0.636 \mathrm{eV})$, implying that it is easier to obtain electron, thus effectively restraining the decomposition of $\mathrm{H}_{2} \mathrm{O}$. In addition, the anti-corrosion ability was also studied through a linear voltammetry test (Fig. 2f). The introduce of veratraldehyde was capable of reducing the corrosion current from 2.78 to $0.0333 \mathrm{~mA} \mathrm{~cm}^{-2}$, indicating that this additive would bring effective restriction for various of side-reactions during the Zn plating/stripping process. All of these illustrated that higher capability of inhibiting the decomposition of active $\mathrm{H}_{2} \mathrm{O}$ molecules and growth of various by-products could be achieved when the veratraldehyde was added into the pure $\mathrm{ZnSO}_{4}$ electrolyte.

To get a deeper understanding in the function of the veratraldehyde additive, CV curves for reversible $\mathrm{Zn}$ plating/stripping measurements on Ti were collected. As can be seen in Fig. S7a, a pair of stripping/plating peaks were easily found at around -0.80 and $-1.20 \mathrm{~V}$ (versus $\mathrm{Ag}$ / $\mathrm{AgCl}$ ) in nearly each cycle under a pure $\mathrm{ZnSO}_{4}$ electrolyte. In contrast, when the veratraldehyde was introduced into the electrolyte system, there appeared one more pair of redox peaks except that for $\mathrm{Zn}$ plating/stripping process presented in Fig. $2 \mathrm{~g}$ at the first five $\mathrm{CV}$ cycles, which should be originated from the redox process of the reversible transformation between the veratraldehyde additive and veratryl alcohol molecules (see formula in Fig. S8). It's worth noticing that the extra pair of peaks located at around -0.95 and $-1.15 \mathrm{~V}$ were all prior to the dissolution/deposition of $\mathrm{Zn}$, which was helpful for slowing the $\mathrm{Zn}$ plating/stripping speed and resulted in constrained 2D diffusion process. Their corresponding chronocoulometry curves according to $\mathrm{CV}$ measurements at specific cycles were then calculated (Figs. S7b and $2 \mathrm{~h}$ ). The coulombic efficiency (CE) under pure $\mathrm{ZnSO}_{4}$ electrolyte demonstrated an irregular flucturation among different cycles, all lower than $85 \%$, while for the $\mathrm{ZnSO}_{4}$-veratraldehyde electrolyte system, CE value gradually increased to over $90 \%$, indicating that the veratraldehyde additive contributed to more stable $\mathrm{Zn}$ plating/stripping behaviors. To figure out detailed chemical reaction of the veratraldehyde additive accompanying the main process of reversible $\mathrm{Zn} / \mathrm{Zn}^{2+}$ conversion in the electrode/electrolyte interface, several DFT calculations were applied again. As depicted in Fig. 2i, the $\mathrm{C}=\mathrm{O}$ bond from its aldehyde group owns the lowest electrostatic potential, thus becoming the nucleophilic site during reduction process. Furthermore, the free-energy variation of the reduction process of a veratraldehyde molecule absorbed on $\mathrm{Zn}(002)$ slab was studied in Fig. 2j, where two possible reaction paths all including three steps were compared. It can be inferred that the aldehyde group from the veratraldehyde molecule prefer to acquire proton on $\mathrm{C}$ atom and finally reach the totally reduced state-veratryl alcohol. $\Delta \mathrm{G}$ of this reaction $(-0.47 \mathrm{eV})$ was lower than that of HER process mentioned above $(\Delta \mathrm{G}=-0.67 \mathrm{eV})$, indicating the reduction of the veratraldehyde happened in priority. It should be noted that even some veratraldehyde additives were reduced to veratryl alcohol molecules, their absorption on $\mathrm{Zn}$ slab is also capable of suppressing the production of $\mathrm{H}_{2}$ while decrease the corrosion current at the same time, as proved by the DFT calculation and electrochemical test results in Fig. S9.

After studying the insight mechanism in inhibiting $\mathrm{Zn}$ dendrite/by-products growth of the veratraldehyde additive in microscale (several nanometers) via DTF methods, finite element analysis (FEA) in macroscale (hundreds of micrometers) was further conducted to observe its obvious function. As demonstrated in Fig. 3a-c, the electric field intensity for the tip of one dendrite nuclear obviously exhibit much larger value than those area at the bottom space. Therefore, dendrites prefer to grow higher as the depositing time was prolonged to a period of time. Strikingly, the addition of veratraldehyde is evidently able to influence the distribution of electric field intensity, that is, badly impair their intensity in the tip of the dendrite core to lower than those at the bottom space, as presented in Fig. 3d-f. Besides, after enough deposition time ( 300 and $600 \mathrm{~s}$ ), the $\mathrm{Zn}$ dendrite can be filled to a smaller state and leveled up finally (Fig. S10).

Concluding the above experimental and theory analysis, the comprehensive mechanism for controlling the production of $\mathrm{Zn}$ dendrites/by-products of the veratraldehyde additive can be described, as demonstrated in schemes of Fig. 3g, h. In traditionally pure $\mathrm{ZnSO}_{4}$ electrolyte, detrimental $\mathrm{H}_{2} \mathrm{O}$ molecules distributed in the $\mathrm{Zn}$ anode interface can be easily ionized into $\mathrm{H}^{+}$and $\mathrm{OH}^{-}$. On the $\mathrm{Zn}$ surface with abundant electrons, aggregated $\mathrm{H}^{+}$ions are easily reduced to $\mathrm{H}_{2}$ and stay away from the electrolyte system, leaving 
much $\mathrm{OH}^{-}$and increasing the $\mathrm{pH}$ vales. These usually lead to rampant side-reactions including corrosion of $\mathrm{Zn}$ metal and generation of common by-products. Besides, the deposition process of $\mathrm{Zn}^{2+}$ is violent and uncontrollable, resulting in uneven growth of $\mathrm{Zn}$ dendrite and even breaking away from $\mathrm{Zn}$ anode into dead $\mathrm{Zn}$. The introduced veratraldehyde additive is inclined to absorb on $\mathrm{Zn}$ anode surface before $\mathrm{H}_{2} \mathrm{O}$ molecules and $\mathrm{Zn}^{2+}$ ions, thus achieving the following effects: (1) It can effectively inhibit the HER process, thus retaining the $\mathrm{pH}$ of electrolyte in a proper value and suppressing the occurrence of all kinds of side-reactions; (2) Redox reactions between the veratraldehyde and veratryl alcohol are prior to the $\mathrm{Zn}$ stripping/plating process, which is helpful for controlling the rampant $2 \mathrm{D}$ diffusion process and bringing uniform deposition/dissolution of $\mathrm{Zn}$ through a competition behavior.

\subsection{All Kinds of Cells Evaluation}

To further affirm the attracting function of the veratraldehyde additive in stabilizing $\mathrm{Zn}$ anodes during reversible plating/stripping reactions, $\mathrm{Zn}-\mathrm{Zn}, \mathrm{Zn}-\mathrm{Ti}$ and $\mathrm{Zn}-\mathrm{MnO}_{2}$ cells were all fabricated to study its effect in actual energy storage devices. Firstly, cycling stability of Zn-Zn symmetric cells in several current densities and deposited capacities with different electrolyte systems were compared, as presented in Fig. $4 \mathrm{a}-\mathrm{c}$. In pure $\mathrm{ZnSO}_{4}$ electrolyte, under the testing condition of $1 \mathrm{~mA} \mathrm{~cm} / 1 \mathrm{mAh} \mathrm{cm}^{-2}$ and $2 \mathrm{~mA} \mathrm{~cm}^{-2} / 2 \mathrm{mAh} \mathrm{cm}^{-2}$, the symmetric cells encountered short circuit induced by developed $\mathrm{Zn}$ dendrite all at around $150 \mathrm{~h}$. After the addition of the veratraldehyde additive, $\mathrm{Zn}-\mathrm{Zn}$ cells can achieve a super-long cycling life of over $3200 \mathrm{~h}, 900 \mathrm{~h}$ under $1 \mathrm{~mA} \mathrm{~cm}^{-2} / 1 \mathrm{mAh} \mathrm{cm}^{-2}$,
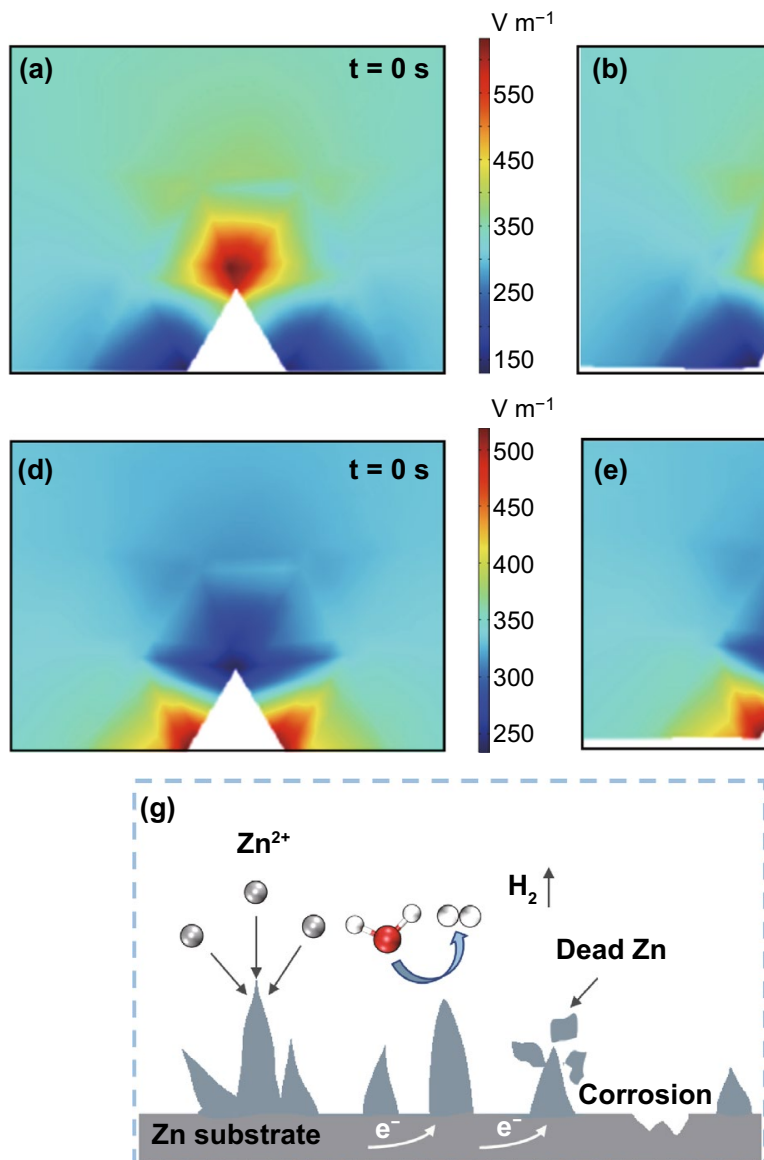
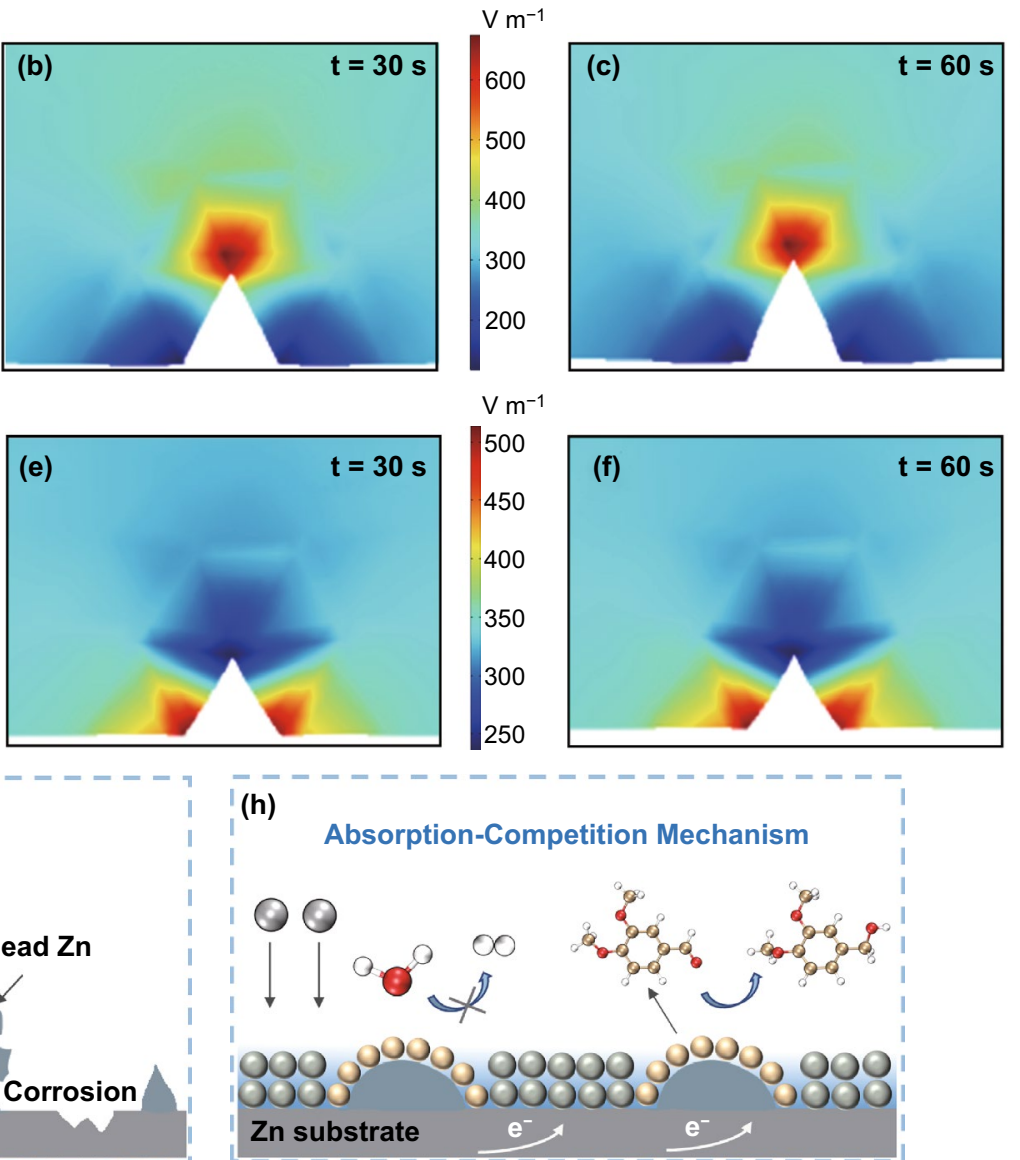

Fig. 3 Finite Element Analysis for electric field intensity in $\mathrm{Zn}$ anode surface under different electrolyte systems and the scheme describing the inhibiting mechanism for dendrite growth of veratraldehyde. Models of electric field intensity distribution under a-c pure $\mathrm{ZnSO}_{4}$ and $\mathbf{d}-\mathbf{f}$ $\mathrm{ZnSO}_{4}$-veratraldehyde electrolytes at different deposition time; Schemes of electrochemical reactions in $\mathrm{Zn}$ anode/electrolyte interface under $\mathbf{g}$ $\mathrm{ZnSO}_{4}$ and $\mathbf{h} \mathrm{ZnSO}_{4}$-veratraldehyde electrolytes 
$2 \mathrm{~mA} \mathrm{~cm}{ }^{-2} / 2 \mathrm{mAh} \mathrm{cm}^{-2}$, respectively, and great stability (over $800 \mathrm{~h}$ ) even at a high current density/capacity of $5 \mathrm{mAcm}^{-2} / 5 \mathrm{mAh} \mathrm{cm}^{-2}$, much better than that with pure $\mathrm{ZnSO}_{4}$ electrolyte $(54 \mathrm{~h})$ and most of the previous work (Fig. 4d) [12, 14, 20, 23, 32, 33, 35, 50, 51]. Moreover, the veratraldehyde also can ensure stable rate cycling performance in $\mathrm{Zn}-\mathrm{Zn}$ cells (Fig. S11a) under conditions ranging from $1 \mathrm{~mA} \mathrm{~cm}{ }^{-2} / 1 \mathrm{mAh} \mathrm{cm}^{-2}, 2 \mathrm{~mA} \mathrm{~cm}{ }^{-2} / 2 \mathrm{mAh} \mathrm{cm}^{-2}$, $5 \mathrm{mAcm}^{-2} / 5 \mathrm{mAh} \mathrm{cm}^{-2}$ and finally back to $1 \mathrm{~mA} \mathrm{~cm}^{-2} / 1$

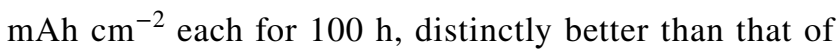
pure $\mathrm{ZnSO}_{4}$ electrolyte (Fig. S11b). Proper concentration of the veratraldehyde additive was further studied, as demonstrated in Fig. S12. Gradually increasing amount of veratraldehyde (before $0.3 \mathrm{~g} \mathrm{~L}^{-1}$ ) can effectively boost the cycling stability of $\mathrm{Zn}-\mathrm{Zn}$ cells. After the concentration was further increased to $0.4 \mathrm{~g} \mathrm{~L}^{-1}$ (close to its solubility limit), no obvious enhancement in stability could be observed, but resulting a larger polarization voltage. Therefore, $0.3 \mathrm{~g} \mathrm{~L}^{-1}$ was selected as the final concentration. It is worth noting that $\mathrm{Zn}-\mathrm{Zn}$ cells under the $\mathrm{ZnSO}_{4}$ electrolyte with a veratryl alcohol additive can also achieve great performance (over $320 \mathrm{~h}$ at $5 \mathrm{mAcm}^{-2} / 5 \mathrm{mAh} \mathrm{cm}^{-2}$, as shown in Fig. S13), demonstrating that even though some veratraldehyde molecules were reduced to veratryl alcohol during long-term test, the $\mathrm{Zn}$ anode could still be well protected both by the rest veratraldehyde and new formed veratryl alcohol. Subsquently, Zn plating/stripping coulombic efficiency (CE) was evaluated via constructing $\mathrm{Zn}-\mathrm{Ti}$ cells under different electrolytes. As exhibited in Fig. S14, at first 80 cycles, $\mathrm{Zn}$-Ti cells with pure $\mathrm{ZnSO}_{4}$ electrolyte possess stable $\mathrm{CE}$ and then appears fluctuate as a result of the uncontrollable growth of dendrite or several by-products. However for veratraldehyde- $\mathrm{ZnSO}_{4}$ environment, $\mathrm{CE}$ of $\mathrm{Zn}-\mathrm{Ti}$ cells continued to increase and all reached over 97\% after 100 cycles, indicating excellent repellency for all kinds of side-reactions and fierce dendrite growth.

The $\mathrm{Zn}-\mathrm{MnO}_{2}$ full cells were finally assembled through combining electrodeposited $\mathrm{MnO}_{2}$ on carbon cloth and $\mathrm{Zn}$ foil to study the practical availability in energy storage devices of the veratraldehyde additive. It can be clearly found that the introduction of the veratraldehyde additive is capable of elevating overall performance of full cells. As indicated in Figs. 4e and S15, the rate performance and corresponding galvanostatic charge-discharge (GCD) curves at a current density of $0.1 \mathrm{~A} \mathrm{~g} \mathrm{~g}^{-1}$ comparisons were collected. Obviously, devices with the veratraldehyde additive performed comparable mass specific capacity than that of pure $\mathrm{ZnSO}_{4}$ electrolyte under different current densities, implying the addition of veratraldehyde hardly influence the energy storage ability of practical devices. $\mathrm{CV}$ cures of the $\mathrm{Zn}-\mathrm{MnO}_{2}$ full cells with a veratraldehyde- $\mathrm{ZnSO}_{4}$ electrolyte under different scan rates showed two pair of redox peaks, which was related to the two-steps $\mathrm{Zn}^{2+}$ insertion/extraction process for the $\mathrm{MnO}_{2}$ cathode (Fig. S16). As for cycling stability (shown in Fig. 4f-h), the full cells with the veratraldehyde additive achieved much better performance than that of pure $\mathrm{ZnSO}_{4}$ electrolyte, with a capacity retention of $75.4 \%$ over $45.5 \%$ after 1000 GCD cycles at a current density of 1 $\mathrm{A} \mathrm{g}^{-1}$. The prevention ability for parasitic reactions of the veratraldehyde additive inside full cells can also be proved via the GCD and self-discharge measurements. $\mathrm{Zn}-\mathrm{MnO}_{2}$ devices with different electrolyte systems were all charged to $1.9 \mathrm{~V}$, subsquently rested for $48 \mathrm{~h}$ and finally discharged to $1 \mathrm{~V}$ (Fig. 4i, j). There existed remarkable difference in CE value with different electrolytes $(95.3 \%$ for veratraldehyde$\mathrm{ZnSO}_{4}$ and $81.7 \%$ for pure $\mathrm{ZnSO}_{4}$ ), demonstrating the excellent function of the veratraldehyde in restraining all kinds of side-reactions.

\subsection{Universality of Aromatic Aldehyde-Based Additive for Stabilizing Zn Anode}

At last, for confirming the universal effect of aromatic aldehyde type additives for obtaining stable $\mathrm{Zn}$ plating/stripping process, two more kinds of aromatic aldehyde, anisaldehyde (usually found in citronella) and vanillin (usually found in vanilla) were selected. As demonstrated in Fig. 5a, b, their electrostatic potential mappings were firstly calculated, indicating their nucleophilic sites still located at the $\mathrm{C}-\mathrm{O}$ bond from the aldehyde group, the same as the veratraldehyde. As a proof of concept, $\mathrm{Zn}-\mathrm{Zn}$ symmetric cells with these two additives were constructed, and their reversible plating/stripping stability were studied, as presented in Figs. 5c, d and $\mathrm{S} 17$. For anisaldehyde- $\mathrm{ZnSO}_{4}$ system, the symmetric cells reached over $3000 \mathrm{~h}$ and $200 \mathrm{~h}$ cycles for testing conditions of $1 \mathrm{~mA} \mathrm{~cm} / 1 \mathrm{mAh} \mathrm{cm}^{-2}$ and $5 \mathrm{~mA} \mathrm{~cm} / 5 \mathrm{mAh} \mathrm{cm}^{-2}$, respectively, while for the vanillin- $\mathrm{ZnSO}_{4}$ one, $1800 \mathrm{~h}$ and $300 \mathrm{~h}$ cycles under measurement conditions of $1 \mathrm{~mA} \mathrm{~cm}^{-2} / 1$ $\mathrm{mAh} \mathrm{cm} \mathrm{c}^{-2}$ and $5 \mathrm{~mA} \mathrm{~cm} \mathrm{mAh} \mathrm{cm}^{-2} / 5 \mathrm{mAre}^{-2}$ achieved, all much better than that of pure $\mathrm{ZnSO}_{4}$ system. 

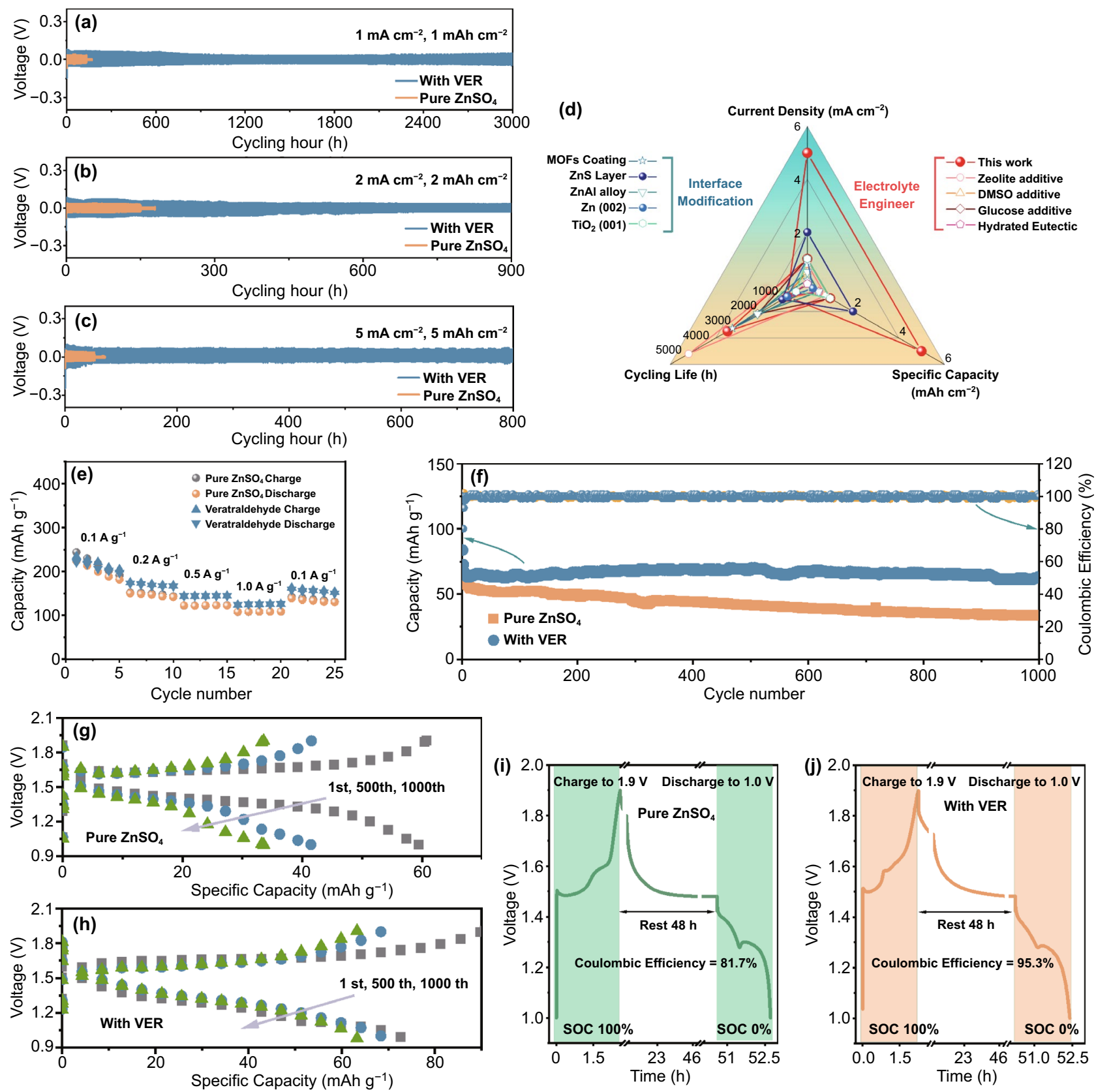

Fig. 4 Performance comparison of $\mathrm{Zn}-\mathrm{Zn}, \mathrm{Zn}-\mathrm{Ti}$ and $\mathrm{Zn}-\mathrm{MnO}_{2}$ cells under different electrolyte environments. Long-term cycling performance comparison of $\mathrm{Zn}-\mathrm{Zn}$ symmetric cells under different current densities and areal capacities of $\mathbf{a} 1 \mathrm{~mA} \mathrm{~cm}{ }^{-2}, 1 \mathrm{mAh} \mathrm{cm}^{-2}, \mathbf{b} 2 \mathrm{~mA} \mathrm{~cm}^{-2}, 2 \mathrm{mAh}$ $\mathrm{cm}^{-2}$ and $\mathbf{c} 5 \mathrm{~mA} \mathrm{~cm}{ }^{-2}, 5 \mathrm{mAh} \mathrm{cm}{ }^{-2}$ in different electrolytes; $\mathbf{d}$ performance comparison of $\mathrm{Zn}-\mathrm{Zn}$ symmetric cells between this work and previous work; $\mathbf{e}$ rate capacities at different current densities ranging from 0.1 to $1.0 \mathrm{~A} \mathrm{~g}^{-1}$, $\mathbf{f}$ cycling stability at a current density of $3.08 \mathrm{~A} \mathrm{~g}^{-1}$ and $\mathbf{g}$, $\mathbf{h}$ corresponding galvanostatic curves of $\mathrm{Zn}-\mathrm{MnO}_{2}$ full cells under different electrolyte systems; Self-discharge performance of $\mathrm{Zn}-\mathrm{MnO}_{2}$ full cells under $\mathbf{i}$ pure $\mathrm{ZnSO}_{4}$ and $\mathbf{j} \mathrm{ZnSO}_{4}$-veratraldehyde electrolytes

\section{Conclusions}

In summary, we proposed some aromatic aldehyde molecules as a kind of electrolyte additives in traditional $\mathrm{ZnSO}_{4}$ electrolyte for $\mathrm{Zn}$ ion batteries and achieved great performance in stabilizing $\mathrm{Zn}$ anodes. Choosing one of the most common aromatic aldehydes, veratraldehyde as an example, unique realization mechanism in inhibiting the growth of $\mathrm{Zn}$ dendrite/by-products was explored. Combing various electrochemical measurements and DFT 

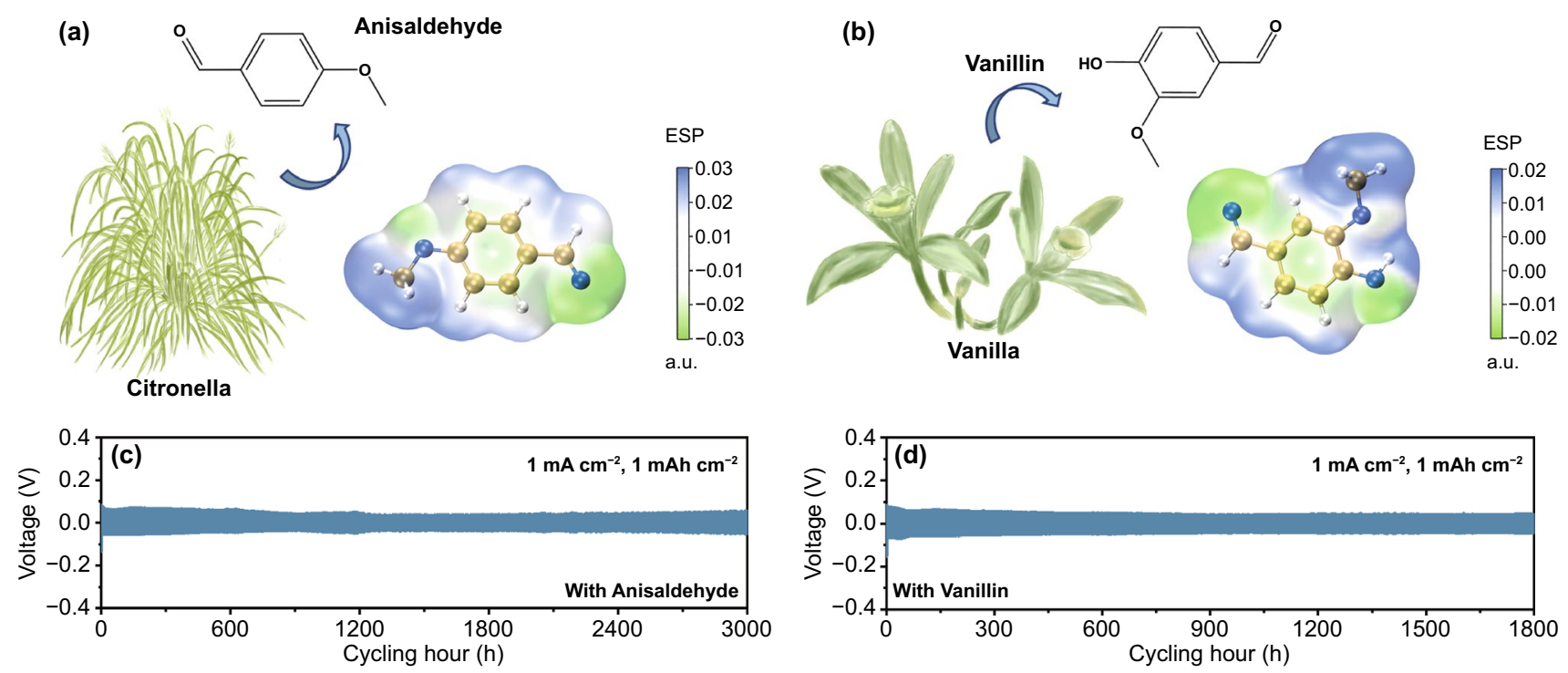

Fig. 5 Universal application of different aromatic aldehydes as additive for suppressing Zn dendrite. Schemes indicating two commonly used aromatic aldehydes a anisaldehyde, $\mathbf{b}$ vanillin and their corresponding molecular structure, electrostatic potential mapping; Long-term cycling performances of $\mathrm{Zn}-\mathrm{Zn}$ symmetric cells at a current density and areal capacity of $1 \mathrm{~mA} \mathrm{~cm}{ }^{-2}, 1 \mathrm{mAh} \mathrm{cm}^{-2}$ under $\mathbf{c} \mathrm{ZnSO}_{4}$-anisaldehyde and d $\mathrm{ZnSO}_{4}$-vanillin electrolytes

calculations, it can be inferred that the veratraldehyde is prone to absorb on the $\mathrm{Zn}$ surface than $\mathrm{H}_{2} \mathrm{O}$ and $\mathrm{Zn}^{2+}$, preventing the conventional HER reactions derived from the decomposition of active $\mathrm{H}_{2} \mathrm{O}$ molecules around the $\mathrm{Zn}$ anode interface and uncontrollable deposition of $\mathrm{Zn}^{2+}$. Furtherly, veratraldehyde molecules owned a lower redox potential than that of Zn plating/stripping, which efficiently stabilized the initial nucleation process of deposited $\mathrm{Zn}$ layer and further limited those side-reactions including HER, corrosion and increase of dead $\mathrm{Zn}$ metal via a competing process. Macroscopic FEA simulations indicated that the absorption of the veratraldehyde is capable of impairing the electric field intensity in the tip of dendrite nuclear, thus resulting a final plain plating layer. As a prove of concept, $\mathrm{Zn}-\mathrm{Zn}$ symmetric cells with a veratraldehyde additive can reach a superlong cycling life of $3200 \mathrm{~h}$ at a current density/capacity of $1 \mathrm{~mA} \mathrm{~cm}^{-2} / 1 \mathrm{mAh} \mathrm{cm}^{-2}$, and over $800 \mathrm{~h}$ at $5 \mathrm{~mA} \mathrm{~cm}{ }^{-2} / 5$ $\mathrm{mAh} \mathrm{cm}{ }^{-2}$, far more than those of with pure $\mathrm{ZnSO}_{4}$ electrolyte (150 and $54 \mathrm{~h}$, respectively). Besides, $\mathrm{Zn}-\mathrm{Ti}$ cell using $\mathrm{ZnSO}_{4}$-veratraldehyde electrolyte demonstrated great $\mathrm{CE}$ (over $97 \%$ for over 200 cycles), obviously more stable than that of pure $\mathrm{ZnSO}_{4}$ system. Furtherly, $\mathrm{Zn}-\mathrm{MnO}_{2}$ full cells under a $\mathrm{ZnSO}_{4}$-veratraldehyde environment exhibited much better cycling stability and self-discharge $\mathrm{CE}$, implying the excellent function of the veratraldehyde in stabilizing the
$\mathrm{Zn}$ anode and whole practical cells. Finally, two more other aromatic aldehyde, anisaldehyde and vanillin were chosen to prove their universality as additives for stable $\mathrm{Zn}$ anode in $\mathrm{Zn}$ ion batteries. $\mathrm{Zn}-\mathrm{Zn}$ symmetric cells using above two additives all realized outstanding cycling stability at several measuring conditions, indicating the aromatic aldehydebased additives could be one of the attractive candidates in future electrolyte engineer design and commercial use of all kinds of Zn-based energy storage devices.

Acknowledgements Dr. G. F. Cui gratefully acknowledges the financial support by National Natural Science Foundation of China $(51271205,50801070)$, "Project of Science and Technology Plan” by Qingyuan city (DZXQY052, 2018C005, 2019A026), Project of results transformation achievement fund by Sun Yat-sen University (31000-18843232), “Tian'e Plan'” by Huizhou city (20170220011822281, 20170220085037390) and the Scientifc Technology Project of Guangzhou City (202103000003).

Funding Open access funding provided by Shanghai Jiao Tong University.

Open Access This article is licensed under a Creative Commons Attribution 4.0 International License, which permits use, sharing, adaptation, distribution and reproduction in any medium or format, as long as you give appropriate credit to the original author(s) and the source, provide a link to the Creative Commons licence, and indicate if changes were made. The images or other third party material in this article are included in the article's Creative 
Commons licence, unless indicated otherwise in a credit line to the material. If material is not included in the article's Creative Commons licence and your intended use is not permitted by statutory regulation or exceeds the permitted use, you will need to obtain permission directly from the copyright holder. To view a copy of this licence, visit http://creativecommons.org/licenses/by/4.0/.

Supplementary Information The online version contains supplementary material available at https://doi.org/10.1007/ s40820-021-00777-2.

\section{References}

1. D. Chao, W. Zhou, F. Xie, C. Ye, H. Li et al., Roadmap for advanced aqueous batteries: from design of materials to applications. Sci. Adv. 6(21), aba4098 (2020). https://doi.org/10. 1126/sciadv.aba4098

2. M. Song, H. Tan, D. Chao, H.J. Fan, Recent advances in Znion batteries. Adv. Funct. Mater. 28(41), 1802564 (2018). https://doi.org/10.1002/adfm.201802564

3. Y.P. Deng, R. Liang, G. Jiang, Y. Jiang, A. Yu et al., The current state of aqueous $\mathrm{Zn}$-based rechargeable batteries. ACS Energy Lett. 5(5), 1665-1675 (2020). https://doi.org/10.1021/ acsenergylett.0c00502

4. X. Zeng, J. Hao, Z. Wang, J. Mao, Z. Guo, Recent progress and perspectives on aqueous $\mathrm{Zn}$-based rechargeable batteries with mild aqueous electrolytes. Energy Storage Mater. 20, 410-437 (2019). https://doi.org/10.1016/j.ensm.2019.04.022

5. D. Chao, W. Zhou, C. Ye, Q. Zhang, Y. Chen et al., An electrolytic $\mathrm{Zn}-\mathrm{MnO}_{2}$ battery for high-voltage and scalable energy storage. Angew. Chem. Int. Ed. 58(23), 7823-7828 (2019). https://doi.org/10.1002/anie.201904174

6. Q. Yang, Q. Li, Z. Liu, D. Wang, Y. Guo et al., Dendrites in Zn-based batteries. Adv. Mater. 32(48), 2001854 (2020). https://doi.org/10.1002/adma.202001854

7. Z. Yi, G. Chen, F. Hou, L. Wang, J. Liang, Strategies for the stabilization of $\mathrm{Zn}$ metal anodes for $\mathrm{Zn}$-ion batteries. Adv. Energy Mater. 11(1), 2003065 (2021). https://doi.org/10.1002/ aenm.202003065

8. Z. Cao, P. Zhuang, X. Zhang, M. Ye, J. Shen et al., Strategies for dendrite-free anode in aqueous rechargeable zinc ion batteries. Adv. Energy Mater. 10(30), 2001599 (2020). https:// doi.org/10.1002/aenm.202001599

9. J. Hao, X. Li, X. Zeng, D. Li, J. Mao et al., Deeply understanding the $\mathrm{Zn}$ anode behaviour and corresponding improvement strategies in different aqueous Zn-based batteries. Energy Environ. Sci. 13(11), 3917-3949 (2020). https://doi.org/10. 1039/d0ee02162h

10. H. Yang, Z. Chang, Y. Qiao, H. Deng, X. Mu et al., Constructing a super-saturated electrolyte front surface for stable rechargeable aqueous zinc batteries. Angew. Chem. Int. Ed. 59(24), 9377-9381 (2020). https://doi.org/10.1002/anie.202001844

11. N. Zhang, S. Huang, Z. Yuan, J. Zhu, Z. Zhao et al., Direct self-assembly of MXene on $\mathrm{Zn}$ anodes for dendrite-free aqueous zinc-ion batteries. Angew. Chem. Int. Ed. 60(6), 2861-2865 (2021). https://doi.org/10.1002/anie.202012322

12. J. Hao, B. Li, X. Li, X. Zeng, S. Zhang et al., An in-depth study of $\mathrm{Zn}$ metal surface chemistry for advanced aqueous Zn-ion batteries. Adv. Mater. 32(34), 2003021 (2020). https:// doi.org/10.1002/adma.202003021

13. Z. Wang, J. Huang, Z. Guo, X. Dong, Y. Liu et al., A metalorganic framework host for highly reversible dendrite-free zinc metal anodes. Joule 3(5), 1289-1300 (2019). https://doi.org/ 10.1016/j.joule.2019.02.012

14. Q. Zhang, J. Luan, X. Huang, Q. Wang, D. Sun et al., Revealing the role of crystal orientation of protective layers for stable zinc anode. Nat. Commun. 11, 3961 (2020). https://doi.org/10. 1038/s41467-020-17752-X

15. J. Hao, X. Li, S. Zhang, F. Yang, X. Zeng et al., Designing dendrite-free zinc anodes for advanced aqueous zinc batteries. Adv. Funct. Mater. 30(30), 2001263 (2020). https://doi.org/10. 1002/adfm.202001263

16. H. Qiu, X. Du, J. Zhao, Y. Wang, J. Ju et al., Zinc anode-compatible in-situ solid electrolyte interphase via cation solvation modulation. Nat. Commun. 10, 5374 (2019). https://doi.org/ 10.1038/s41467-019-13436-3

17. J. Zhi, S. Li, M. Han, P. Chen, Biomolecule-guided cation regulation for dendrite-free metal anodes. Sci. Adv. 6(32), abb1342 (2020). https://doi.org/10.1126/sciadv.abb1342

18. J. Cao, D. Zhang, C. Gu, X. Wang, S. Wang et al., Manipulating crystallographic orientation of zinc deposition for dendrite-free zinc ion batteries. Adv. Energy Mater. 11(29), 2101299 (2021). https://doi.org/10.1002/aenm.202101299

19. K. Wu, J. Yi, X. Liu, Y. Sun, J. Cui et al., Regulating Zn deposition via an artificial solid-electrolyte interface with aligned dipoles for long life $\mathrm{Zn}$ anode. Nano-Micro Lett. 13, 79 (2021). https://doi.org/10.1007/s40820-021-00599-2

20. S.B. Wang, Q. Ran, R.Q. Yao, H. Shi, Z. Wen et al., Lamella-nanostructured eutectic zinc-aluminum alloys as reversible and dendrite-free anodes for aqueous rechargeable batteries. Nat. Commun. 11, 1634 (2020). https://doi. org/10.1038/s41467-020-15478-4

21. B. Liu, S. Wang, Z. Wang, H. Lei, Z. Chen et al., Novel 3D nanoporous $\mathrm{Zn}-\mathrm{Cu}$ alloy as long-life anode toward highvoltage double electrolyte aqueous zinc-ion batteries. Small 16(22), 2001323 (2020). https://doi.org/10.1002/smll.20200 1323

22. Q. Zhang, J. Luan, L. Fu, S. Wu, Y. Tang et al., The threedimensional dendrite-free zinc anode on a copper mesh with a zinc-oriented polyacrylamide electrolyte additive. Angew. Chem. Int. Ed. 58(44), 15841-15847 (2019). https://doi.org/ 10.1002/anie.201907830

23. D. Yuan, J. Zhao, H. Ren, Y. Chen, R. Chua et al., Anion texturing towards dendrite-free $\mathrm{Zn}$ anode for aqueous rechargeable batteries. Angew. Chem. Int. Ed. 60(13), 7213-7219 (2021). https://doi.org/10.1002/anie.202015488

24. J. Zheng, Q. Zhao, T. Tang, J. Yin, C.D. Quilty et al., Reversible epitaxial electrodeposition of metals in battery anodes. Science 366(6465), 645-648 (2019). https://doi.org/ $10.1126 /$ science.aax 6873 
25. J. Zheng, J. Yin, D. Zhang, G. Li, D.C. Bock et al., Spontaneous and field-induced crystallographic reorientation of metal electrodeposits at battery anodes. Sci. Adv. 6(25), abb1122 (2020). https://doi.org/10.1126/sciadv.abb1122

26. M. Zhou, S. Guo, J. Li, X. Luo, Z. Liu et al., Surface-preferred crystal plane for a stable and reversible zinc anode. Adv. Mater. 2100187 (2021). https://doi.org/10.1002/adma. 202100187

27. Z. Wang, L. Dong, W. Huang, H. Jia, Q. Zhao et al., Simultaneously regulating uniform $\mathrm{Zn}^{2+}$ flux and electron conduction by $\mathrm{MOF} / \mathrm{rGO}$ interlayers for high-performance $\mathrm{Zn}$ anodes. Nano-Micro Lett. 13, 73 (2021). https://doi.org/10. 1007/s40820-021-00594-7

28. J. Hao, L. Yuan, C. Ye, D. Chao, K. Davey et al., Boosting zinc electrode reversibility in aqueous electrolytes by using low-cost antisolvents. Angew. Chem. Int. Ed. 60(13), 7366-7375 (2021). https://doi.org/10.1002/anie.202016531

29. A. Bayaguud, X. Luo, Y. Fu, C. Zhu, Cationic surfactanttype electrolyte additive enables three-dimensional dendritefree zinc anode for stable zinc-ion batteries. ACS Energy Lett. 5(9), 3012-3020 (2020). https://doi.org/10.1021/acsen ergylett.0c01792

30. W. Xu, K. Zhao, W. Huo, Y. Wang, G. Yao et al., Diethyl ether as self-healing electrolyte additive enabled long-life rechargeable aqueous zinc ion batteries. Nano Energy 62, 275-281 (2019). https://doi.org/10.1016/j.nanoen.2019.05. 042

31. P. Wang, X. Xie, Z. Xing, X. Chen, G. Fang et al., Mechanistic insights of $\mathrm{Mg}^{2+}$-electrolyte additive for high-energy and long-life zinc-ion hybrid capacitors. Adv. Energy Mater. 11(30), 2101158 (2021). https://doi.org/10.1002/aenm. 202101158

32. L. Cao, D. Li, E. Hu, J. Xu, T. Deng et al., Solvation structure design for aqueous $\mathrm{Zn}$ metal batteries. J. Am. Chem. Soc. 142(51), 21404-21409 (2020). https://doi.org/10.1021/ jacs.0c09794

33. P. Sun, L. Ma, W. Zhou, M. Qiu, Z. Wang et al., Simultaneous regulation on solvation shell and electrode interface for dendrite-free $\mathrm{Zn}$ ion batteries achieved by a low-cost glucose additive. Angew. Chem. Int. Ed. 133(33), 18395-18403 (2021). https://doi.org/10.1002/ange.202105756

34. F. Wang, O. Borodin, T. Gao, X. Fan, W. Sun et al., Highly reversible zinc metal anode for aqueous batteries. Nat. Mater. 17, 543-549 (2018). https://doi.org/10.1038/ s41563-018-0063-z

35. W. Yang, X. Du, J. Zhao, Z. Chen, J. Li et al., Hydrated eutectic electrolytes with ligand-oriented solvation shells for long-cycling zinc-organic batteries. Joule 4(7), 1557-1574 (2020). https://doi.org/10.1016/j.joule.2020.05.018

36. L. Ma, S. Chen, N. Li, Z. Liu, Z. Tang et al., Hydrogenfree and dendrite-free all-solid-state $\mathrm{Zn}$-ion batteries. Adv. Mater. 32(14), 1908121 (2020). https://doi.org/10.1002/ adma.201908121

37. M. Chen, J. Chen, W. Zhou, X. Han, Y. Yao et al., Realizing an all-round hydrogel electrolyte toward environmentally adaptive dendrite-free aqueous $\mathrm{Zn}-\mathrm{MnO}_{2}$ batteries. Adv.
Mater. 33(9), e2007559 (2021). https://doi.org/10.1002/ adma.202007559

38. Z. Wang, J. Hu, L. Han, Z. Wang, H. Wang et al., A MOFbased single-ion $\mathrm{Zn}^{2+}$ solid electrolyte leading to dendritefree rechargeable $\mathrm{Zn}$ batteries. Nano Energy 56, 92-99 (2019). https://doi.org/10.1016/j.nanoen.2018.11.038

39. Z. Ye, Z. Cao, M.O.L. Chee, P. Dong, P.M. Ajayan et al., Advances in $\mathrm{Zn}$-ion batteries via regulating liquid electrolyte. Energy Storage Mater. 32, 290-305 (2020). https://doi. org/10.1016/j.ensm.2020.07.011

40. N. Zhang, X. Chen, M. Yu, Z. Niu, F. Cheng et al., Materials chemistry for rechargeable zinc-ion batteries. Chem. Soc. Rev. 49(13), 4203-4219 (2020). https://doi.org/10.1039/ c9cs00349e

41. J. Lao, P. Sun, F. Liu, X. Zhang, C. Zhao et al., In situ plasmonic optical fiber detection of the state of charge of supercapacitors for renewable energy storage. Light Sci. Appl. 7, 34 (2018). https://doi.org/10.1038/s41377-018-0040-y

42. M.J. Frisch, G.W. Trucks, H.B. Schlegel, G.E. Scuseria, M.A. Robb et al., Gaussian 09, revision E. 02, Gaussian, Inc. (2009)

43. W. Humphrey, A. Dalke, K. Schulten, VMD: visual molecular dynamics. J. Mol. Graph. 14(1), 33-38 (1996). https:// doi.org/10.1016/0263-7855(96)00018-5

44. T. Lu, F. Chen, Multiwfn: a multifunctional wavefunction analyzer. J. Comput. Chem. 33(5), 580-592 (2012). https:// doi.org/10.1002/jcc. 22885

45. J.P. Perdew, K. Burke, M. Ernzerhof, Generalized gradient approximation made simple. Phys. Rev. Lett. 77, 3865-3868 (1996). https://doi.org/10.1103/PhysRevLett.77.3865

46. V. Wang, N. Xu, J.C. Liu, G. Tang, W.T. Geng, VASPKIT: a user-friendly interface facilitating high-throughput computing and analysis using VASP code. Comput. Phys. Commun. 267, 108033 (2021). https://doi.org/10.1016/j.cpc.2021.108033

47. J. Choi, R. Jung, In-situ XPS study of core-levels of ZnO thin films at the interface with graphene/Cu. J. Korean Phys. Soc. 73, 1546-1549 (2018). https://doi.org/10.3938/jkps.73.1546

48. D. Hua, R.K. Rai, Y. Zhang, T.S. Chung, Aldehyde functionalized graphene oxide frameworks as robust membrane materials for pervaporative alcohol dehydration. Chem. Eng. Sci. 161, 341-349 (2017). https://doi.org/10.1016/j.ces.2016.12. 061

49. C. Huang, X. Zhao, S. Liu, Y. Hao, Q. Tang et al., Stabilizing zinc anodes by regulating the electrical double layer with saccharin anions. Adv. Mater. 2100445 (2021). https://doi.org/10. 1002/adma.202100445

50. H. Yang, Y. Qiao, Z. Chang, H. Deng, P. He et al., A metalorganic framework as a multifunctional ionic sieve membrane for long-life aqueous zinc-iodide batteries. Adv. Mater. 32, 2004240 (2020). https://doi.org/10.1002/adma.202004240

51. H. Yang, Y. Qiao, Z. Chang, H. Deng, X. Zhu et al., Reducing water activity by zeolite molecular sieve membrane for longlife rechargeable zinc battery. Adv. Mater. 2102415 (2021). https://doi.org/10.1002/adma.202102415 